\title{
Internet practice and professional networks in Chilean science: Dependency or progress?
}

\author{
RicARdo B. DuQue, ${ }^{a}$ WeSLey M. SHRUm, ${ }^{b}$ \\ OMAR BARRIGA JR., ${ }^{c}$ GUILLERMO HENRÍQUEZ ${ }^{c}$ \\ a Tulane University, New Orleans, LA, USA \\ ${ }^{\mathrm{b}}$ Louisiana State University, Baton Rouge, LA, USA \\ ${ }^{\mathrm{c}}$ Universidad de Concepcion, Concepcion, Chile
}

\begin{abstract}
The conventional view depicts scientific communities in the developing world as globally isolated and dependent. Recent studies suggest that individual scientists tend to favor either local or international ties. Yet there are good reasons to believe that both kinds of ties are beneficial for knowledge production. Since they allow for the more efficient management of social networks, Internet technologies are expected to resolve this inverse relationship. They are also expected to decentralize access to resources within developing regions that have traditionally reflected an urban male bias. Elaborating upon science, development and social network perspectives, we examine the impact of the Internet in the Chilean scientific community, addressing the questions 'to what extent is Internet use and experience associated with the size of foreign and domestic professional networks?' and 'are professional network resources equitably distributed across regional and demographical dimensions?' We offer results from a communication network survey of 337 Chilean researchers working in both academic departments and research institutes. We introduce a new measure, 'collaboration range', to indicate the extent to which scientists engage in work with geographically dispersed contacts. Results suggest that larger foreign networks are associated with higher email use and diversity, but local networks are smaller with longer use of the Internet. Diversity of email use is also associated with diverse geographical networks. Moreover, Internet use may be reducing the significance of international meetings for scientific collaboration and networking. Finally, results also show that in the Internet age professional network resources are distributed symmetrically throughout the Chilean scientific community.
\end{abstract}

\section{Introduction}

Studies that focus on how First World scientists use the Internet have consistently taken a positive orientation towards its adoption. Often cited are the co-location benefits of digitally mediated communication and file sharing. These readily allow for collaboration as well as dissemination of scientific information across national and disciplinary boundaries [SPROULL \& KIESLER, 1991; WelLMAN \& AL., 1996, WALSH \& BYMA, 1996; QUAN-HAASE \& WELLMAN, 2004; FinOlt \& OlsON, 1997; ABELS \& AL., 1996; CAStells, 2000; GalimberTi \& AL., 2001; KoKU \& Wellman, 2002; Hine, 2006].

Received August 13, 2008

Address for correspondence:

RICARDO B. DUQUE

E-mail: rduque@tulane.edu

$0138-9130 /$ US $\$ 20.00$

Copyright (C) 2009 Akadémiai Kiadó, Budapest

All rights reserved 
DUQUE \& AL.: Internet practice and professional networks in Chilean science

Internet-mediated collaboration is generally thought to increase scientific productivity, although studies systematically measuring this association have had mixed results [DUQue \& AL., 2005; Hine, 2006; OlsON \& AL., 2008]. But the Internet has been anointed as more than just a tool for making scientific work more efficient, productive and cost effective. It is also predicted to democratize and decentralize access to information, while it extends the social network reach for those who have access to it [DimagGio \& AL., 2001; CASTElls, 2000; FinOlT, 2002; FuchS, 2008]. So profound are its expected structural impacts that the Information Revolution (fueled in large part by the Internet) is suggested to exceed the Industrial Revolution in historical significance [BROWN \& DUGUID, 2000; FUCHS, 2008].

However, while there is a consensus that the Internet is the new 'elixir' for First World progress, there are few studies to date that examine how Internet adoption is shaping professional behavior and outcomes in the Third World. This generally reflects the little work that has been done on scientific communities located in developing regions [VeSsuri, 1987; SAGASTI \& AL., 2003; DUQUE \& AL., 2005]. The studies that do consider contextual variations in the knowledge sector generally contradict the utopist assumption that Internet technology will benefit science regardless of geography or culture [ADAM \& WoOD, 1999; JiMBA \& ATINMO, 2000; EHIKHAMENOR, 2003; DUQUE \& AL., 2005; YNALVEZ \& AL., 2005; YNALVEZ \& SHRUM, 2006]. Although scholars in the developing world may initially approach Internet technologies with the same aims and expectations [COSTA \& MEADOWS, 2000], the results do not always coincide with those of their Northern counterparts. Focusing primarily on research communities located in Africa, India and the Philippines, recent studies conclude that in some resource-poor regions:

1. Internet access is not universal or sustainable.

2. Scientific collaboration in the Internet age does not necessarily lead to increased productivity.

3. Email use does not necessarily circumvent problems of collaboration.

In sum, these empirical investigations support the pessimistic view of technology transfer espoused in urban bias [BRADSHAW, 1987], digital divide [ESCOBAR, 1995; HEDLEY, 1999; ENGELHARD, 1999] and reagency [SHRUM, 2005] perspectives. While the Internet is proving to be an efficient vehicle for progress in the North, according to some scholars it may act as an 'affliction' to development, further widening the knowledge and economic divides between First and Third Worlds.

One way Third World knowledge deficiencies have been framed is by documenting the geographical network configurations and geo-social inequalities found in the scientific communities located in resource-poor regions [SAGASTI \& AL., 2003; DAVIDSON \& AL., 2003]. First, many of these scientific communities engender a dual network identity, either the developing world scientist is well connected to local counterparts or she is well connected to professionals and institutions in the exterior. 
There is rarely a network configuration that is balanced between both local (more likely a strong tie) and global (more likely a weak tie) contacts. ${ }^{1}$ A balance of strong and weak ties is generally considered the optimum social network configuration since each types of contact offers complimentary resources [UZZI, 1996]. In the less developed world, the result is often a disjointed knowledge community, part of which is isolated from global science and part that is exogenously dependent upon agents and institutions located abroad.

Second, in many developing regions, social network and technology resources are often concentrated by urban elites at the expense of rural and semi-urban regions [BRADSHAW, 1987]. Moreover, female scientists face 'patrifocal' constraints in some developing world cultures that limit their access to new technologies and the ability to network outside the domestic arena [PALACKAL \& AL., 2006]. Age is also a social factor that differentiates access to social networks (generally favoring experience and tenure) and technology adoption and use (generally favoring youth) [ROGERS, 1995]. In combination, unequal access to network and technology resources along regional, gender and age dimensions can be grouped together under the phrase 'geo-social asymmetries'. ${ }^{2}$

For optimists, the Internet is the ubiquitous technology that might resolve both the inverse local/global network configuration and re-distribute access to network resources along more equitable geo-social dimensions. By allowing the developing world scientist, regardless of sub-region, gender and age to manage local and global contacts in a cost effective manner, digital technologies could pave the way for a more symmetrical domestic and global scientific community. So far though there has been little systematic attempt to document the Internet's impact on science networks in the developing world.

To address the dearth of investigations in this emerging research area, we assess how the Internet is associated with geographical professional networks in the Chilean

\footnotetext{
${ }^{1}$ This paper does not suggest that all domestic ties are strong and all foreign ties are weak. It does suggest that a domestic contact is more likely to be or develop into a strong tie relationship, while a foreign contact is less likely to be or develop into a strong tie. In many cases during the qualitative phase of this study, returning scholars from abroad reported strong continued collaboration with mentors in the exterior. These tended to fade as careers developed, though [DUQUE, 2007].

${ }^{2}$ In this paper, geo-social inequality refers to the asymmetrical distribution of network resources along regional and social dimensions. There is geo-social symmetry within a given research community if the distribution of professional contacts (resources) is equitably distributed across sub-regions (core, semiperiphery and periphery), among male and female scientists and among researchers in different age cohorts. The regional dimension is of particular interest since traditionally development resources have been concentrated in core or urban regions at the expense of rural ones in many Third World nations [BRADSHAW, 1987]. This is supported in part by MULLIN \& AL.'s [2000] suggestion that a science funding bias favors researchers located in Santiago (the core) over those located in other Chilean regions. Women have traditionally been at a disadvantage in science in terms of support and access to resources [XIE \& SHAUMAN, 2003]. Gender differences are even more marked in some developing nations, where paternalistic cultural systems structurally limit female scientists [PALACKAL \& AL., 2006]. Age has been one of the most stable predictors of technology adoption and use [ROGERS, 1995] and is a particularly important factor in understanding how and why different age cohorts communicate using Internet technologies [DOTY \& AL., 1991].
} 
DUQUE \& AL.: Internet practice and professional networks in Chilean science

scientific community. Chile is a developing nation that is often considered Second World. Once identified for its oppressive military government, over the last two decades it has distinguished itself from other Latin American nations. Since 1989, the country has returned to a democratic form of government, enjoyed steady economic growth and has actively promoted Internet use nationwide [DUQUE, 2007]. It has also experienced a dramatic increase in scientific publication and international collaboration during the first decade of global Internet diffusion [MULLINS \& AL., 2000; HILL, 2004]. Yet, like in many developing nations, there exists an endogenous dislocation among Chilean sectors that challenges the effective translation of scientific discovery into marketable products and national economic development [KRAUSKOPF \& AL., 2007]. For these reasons, Chile offers an ideal developing world case to compare with other more resource-poor regions. Based on a communication-network survey of 337 Chilean academic and research institute scientists, this paper asks (1) 'to what extent is the Chilean scientist's Internet practice associated with her local and international professional network configurations?' and (2)'In the Internet age, are there inequalities in access to network resources by region, gender or age within the Chilean scientific community?' In the following section, we review work on science, development and social networks that frames our investigation, while elaborating upon a novel meta-perspective for categorizing the Internet's possible impacts: the 'elixir', 'affliction' and 'teething' processes. We then outline the methods and measures employed in this study. Finally, we offer findings and conclude with a discussion.

\section{Literature review}

Science studies, development, and social networks perspectives provide a variety of concepts with which to frame the historical impacts of North to South science and technology transfers. The following synthesizes these literatures and outlines a metaperspective by which to categorize the Internet's possible impacts in the developing world as either an 'elixir', 'affliction' or 'teething' process. We end this sub-section with a matrix of alternatives that frame the way Internet use may be associated with geographical network configurations and the geo-social access to professional networks within the Chilean scientific community.

While collaboration and productivity are recent gateway topics into the social studies of science, the implied network impacts of the Internet harkens back to fundamental research on scientific networks and stratification [MERTON, 1968; CRANE, 1971; COZZENS, 1990; SCHOTT, 1993; ZuCKERMAN, 1996]. This early work theorized a stable core-periphery structure in science, where elite researchers and institutions in the core tend to replicate their select status. Meanwhile, scientists at the periphery are marginalized, since gatekeepers located in the core often mediate funding, publications, promotion and prestige. Subsequent studies, though, have neglected to investigate the 
implicit challenge posed by the Internet to this process of accumulative advantage in the First World. Yet, while new information and communication technology use is predicted to elevate the visibility of scientists in remote regions, there are doubts in the North that Internet use improves non-elite scientists" access to "invisible colleges" [FINHOLT, 2002].

Studies that consider developing world researchers' pre-Internet network profiles confirm that they have been structurally isolated from the mainstream of global knowledge production [GAILlARD, 1991; SHRUM \& SHENHAV, 1995; SHRUM \& CAMPION, 1998]. Due to socially unstable and resource poor conditions, they are cut off from sources of funding and access to high impact journals in the exterior. Moreover, the searchable databases for scientific literature have traditionally recognized only a few dissemination outlets available in the developing world [GIBBS, 1995; VOHORA \& VOHORA, 2001; HOLMGREN \& SCHNITZER, 2004]. However, recent advances in scientometric archiving outside the First World are remedying this [MENEGHINI \& AL., 2006; DE MOYA-ANEGÓN \& AL., 2007]. ${ }^{3}$ Historically though, developing world researchers have been functionally invisible to global science [GAILLARD, 1991; DUQUE \& AL., 2005]. Owing to lack of domestic support and perceptions of irrelevance, these scientists are often locally dislocated as well [SAGASTI, 1973; VESSURI, 1987; SAGASTI $\&$ AL., 2003]. They have readily been criticized for expressing 'Ivory Tower' aloofness.

Lack of global visibility and local irrelevance may result from the inverse relationship between domestic and foreign contacts that characterizes many developing world scientists' network profiles [SHRUM \& CAMPION, 1998]. The suggestion is that these scientists' network profiles tend to favor either local or global ties. This, some suggest, indicates a disjointed scientific community that could be maintaining research dependency on the North [SAGASTI \& AL., 2003]. One feature of this exogenous structure is that often developing world scientists are more connected to their counterparts in the First World than they are to scientists and other professionals located in their own regions [SHRUM \& CAMPION, 1998; SAGASTI \& AL., 2003]. Those in the periphery with high levels of foreign contact may be prioritizing Northern research themes, methods, analyses and interpretation at the expense of a focus on local problems and applications. The negative connotation is that over time this process magnifies the knowledge and economic divides between core and periphery regions.

Understanding how the Internet is associated with scientific networks in developing regions has implications for larger developmental debates. The Internet is of particular interest because its global diffusion is often perceived within a modernization or functional equivalence framework as a positive catalyst that streamlines many social,

\footnotetext{
${ }^{3}$ A significant regional expansion of the Web of Science along with contributions from SCImago and Scopus digital archives has enlarged the scope scientometric data to include many sources from Latin America [DE MOYA-ANEGÓN\& AL., 2007]. Moreover, efforts by Scielo in Iberoamerica have also contributed greatly to the visibility of Latin American Science [MENEGHINI \& AL., 2006].
} 
DUQUE \& AL.: Internet practice and professional networks in Chilean science

organizational and technical processes [DIMAGGIO \& AL., 2001; CASTELlS, 2000; GERSHUNY, 2002]. More specific to developing world science, the Internet could act as the 'elixir' that resolves both the inverse local/global network profile and the internal geo-social divide characterizing the scientific communities of many developing regions [DAVIDSON \& AL., 2003; SOORYAMOORTHY \& AL., 2007]. In other words, the Internet may connect the isolated scientist to the global scientific community in a cost effective manner, even as it reconnects the disarticulated and exogenously oriented researcher to local scientific relevancy. Moreover, as many have argued, the Internet will spatially and socially decentralize access and digital benefits throughout a given community [CASTELlS, 2000; FUCHS, 2008]. For example, if she is 'connected,' a young scientist can accrue digital advantages no matter where she is regionally located within the national research community. Network studies conducted outside the North do support some optimism. In a study of Taiwanese academics, HUANG [2007] found that email helped strengthen intra-organizational ties (contacts within one's parent organization), although it did not help strengthen inter-organizational cohesion (contacts outside one's parent organization). In addition, PALACKAL \& AL. [2006] concluded that the Internet is allowing female scientists in India to circumvent 'patrifocal' constraints that have traditionally limited their network reach, compared to their globally-oriented male counterparts.

Differences within and among developing regions, though, may be a result of the historical marginalization experienced by scientists located in underdeveloped countries. With this in mind, some consider the Internet an 'affliction' [DAVIDSON \& AL., 2003; KeNNY, 2006], another example of technologies that exacerbate local and global inequalities [Escobar, 1995; Hedley, 1999; EngelHard, 1999]. Since the North functionally monopolizes the manufacture and innovation of this new technology, the Internet may never diffuse effectively within developing regions. The 'reagency' of the Internet may result in counter-productive use [SHRUM, 2005]. Intended to support increases in local science capacity as it has in the North, it may actually be employed to redirect scientific capacity in impoverished regions. For example, the push and pull forces of asymmetrical global development combined with digital technologies may allow a new population of developing world researchers to have immediate and convenient access to the North. Since the South is more likely to suffer from economic constraints and political instability (push forces), while career opportunities, prestige and resources are concentrated in the North (pull forces), the Internet may accelerate 'brain drain' of the Third World's best and brightest. Moreover where resources are few and concentrated, urban male elites may be more likely to enjoy digital access, thus magnifying geo-social asymmetries within some developing regions. This echoes traditional feminist [XIE \& SHAUMAN, 2003] and urban bias [BRADSHAW, 1987] perspectives. With inconsistent access society-wide, developing world researchers, especially women and those outside core research regions, are more likely to fall farther 
behind their First World counterparts, thus accelerating the global knowledge divide [SAGASTI \& AL., 2003; DUQUE \& AL., 2005].

A third possibility views the Internet as a catalyst for new collaborative links between core and peripheral institutions - a 'teething' process. This may initially result in some negative effects, as predicted by the 'affliction' process, but eventually lead to increases in local integration, capacity and productivity across geo-social dimensions in peripheral regions, as predicted by the 'elixir' process. This argument is closely related to the dependent development perspective that explains the successful tutorial relationship with the West that the Asian Tigers enjoyed over the last half century [GEREFFI, 1989]. DAVIDSON \& AL. [2003] views this as the 'teething' process, since initial difficulties are replaced by long-term positive impacts. For example, the ubiquity of 'Diaspora Networks,' digital communities through which expatriated scientists exchange support and information with colleagues in home countries, highlights the Internet's positive contribution in developing regions over time [MEYER \& WATTIAUX, 2006].

To frame these potential Internet-mediated processes within the social network literature, three ideal types can be identified, representing the 'isolated,' 'disarticulated,' and 'symmetrically connected' scientist. 'Isolated' scientists are exclusively connected through strong ties to research professionals within their home nation. While this group may enjoy the support benefits implied by dense local networks, they sacrifice the avenues for new knowledge and other resources that accrue to those with diverse weak ties [GRANOVETTER, 1973; BURT, 1992; BORGATTI \& JONES, 1998; LIN, 2001]. Within the impoverished context of many developing world scientific communities, these valuable weak tie resources - specialized knowledge, research grants and opportunities for publishing - often flow over links with scientific communities in the exterior. In contrast, the 'disarticulated' scientist is outwardly connected through weak ties to research professionals located in foreign nations and thus enjoys the potential for new resources and information that typically travel through these pathways. But this group of scientists may be drawn more often than not into international collaborations, pursuing research that is 'cutting edge' in external research specialties, but not relevant locally [VeSSURI, 1987; SAGASTI \& AL., 2003]. Moreover, this group sacrifices the multiplex benefits of strong ties that are suggested to be more robust for transferring complex knowledge because these ties tend to be imbedded in a dense web of third party contacts [MurRay \& POOLMAN, 1982; Hansen, 1999; REAGANS \& MCEVILY, 2003]. Perhaps the ideal network profile is that of the 'symmetrically connected scientist', who enjoys both weak and strong professional ties [UzZI, 1996], and a balance of domestic and foreign contacts. This researcher is more likely to benefit from the support of strong professional ties that are local and take advantage of new resources that flow over weak professional links with counterparts in the exterior. 
DUQUE \& AL.: Internet practice and professional networks in Chilean science

In sum, the literature suggests a matrix of six possibilities for Internet-mediated development within scientific communities located in the Third World. These are demonstrated in the following table.

Possible Internet effects on the geographical networks of developing world scientists geographical professional network

\begin{tabular}{|c|c|c|c|}
\hline Geo-social Access & Symmetrical & Foreign Oriented & Domestically Oriented \\
\hline Equal & 1. Elixir & 2. Teething & 3. Teething \\
\hline Unequal & 4. Teething & 5. Affliction & 6. Teething \\
\hline
\end{tabular}

Box 1 suggests an elixir process, where the Internet is associated with both a symmetrical geographical network configuration and network resources that are distributed equitably across gender, age and regional location in the research community. Box 5 suggests a clear affliction process, where the Internet is associated with a foreign oriented network configuration and an asymmetrical distribution of network resources across gender, age and regional location in the research community. The remaining four boxes suggest a continuum of "teething" potentials. Boxes 2, 3 and 4 lean toward an elixir outcome, while box 6 suggests a more challenging process.

In the following, we address the 'elixir', 'affliction' and 'teething' possibilities through an analysis of quantitative data on scientific communication among Chilean scientists. First, we review the methods of the study and the measures employed to tap contextual and educational dimensions, social networks and Internet use. We then present a series of linear regression models in order to examine the factors that predict intra- and inter-organizational networks, local and international networks, collaboration range and geographical diversity.

\section{Methodology}

Bibliometric methods are often used to map collaborative networks in science. Publication databases are organized in ways that allow the number and geographical location of collaborators to be readily accessed and analyzed. Recently, 'webometric' methods have employed the power and ubiquity of the Internet to measure scientific collaboration networks in even more cost affective ways with little loss in reliability [KRETSChMER \& Aguillo, 2004]. These unobtrusive methods though do not capture the totality of professional networks. They only map interlinks that produce publications, although the true value of science networks is distributed across a multiplex range of interactions that include for example moral support, funding, training, professional referrals, and access to new ideas, technologies, methods and upto-date literatures. Moreover, although they have recently expanded to include top 
developing world journals [MENEGHINI \& AL., 2006; DE MOYA-ANEGÓN \& AL., 2007], the databases that bibliometrics have traditionally relied upon have not always offered the most valid measures for capturing collaboration in developing regions [GIBBS, 1995; VOHORA \&VOHORA, 2001; HOLMGREN \& SCHNITZER, 2004].

For these reasons, this present study sought an alternative method for measuring professional networks in the Chilean scientific community. A face-to-face communication network survey was administered to 337 Chilean researchers in the spring of 2005 and summer 2006. ${ }^{4}$ The questionnaire was based on an instrument previously tested in five developing countries covering professional background, collaborative projects and productivity, personal and organizational networks and Internet access and use. ${ }^{5}$ Especially key to this investigation was the capacity of this instrument to document the geographical location of each respondent's close professional contacts and present collaborators. Respondents were selected from a population of university departments (62\%) in one regional center, Concepcion (Universidad de Concepcion) and research institutes (38\%) located in three regional centers, Santiago, Concepcion and Puerto Montt. ${ }^{6}$ The respondents represented the agricultural (34\%), physical (11\%), natural (29\%), engineering (10\%) and social (15\%) sciences. ${ }^{7}$ The average age of academic scientists was approximately 48 years old,

\footnotetext{
${ }^{4}$ Before contacting the respondents, a project administrative assistant first acquired authorization from department or institute directors. Following the initial contact, the respective departments or directors faxed or emailed a list of researchers to be interviewed along with their contact information. Since the study concentrated on a select number of university departments and institutes, all the potential respondents from each unit were sampled. This resulted in a response rate of over 90 percent from academic departments and about 70 percent from research institutes, based on a successfully scheduled and completed face-to-face interview. The refusal rate was passive, due to the researchers' preparation to be in the field or attending outof-town conferences.

${ }^{5}$ The communication survey employed is available online at http://worldsci.net and has been administered in Kerala (India) 1994-2000-2005, Kenya 1994-2001-2005, Ghana 1994-2002-2005, South Africa 2005 and the Philippines 2005.

${ }^{6}$ Of the 129 respondents sampled from research institutes, 28 percent were located in the Santiago area (central), 44 percent in the Concepcion area (mid-south) and 32 percent in the Puerto Montt area (south). Conception is midway between the two other regions, which are separated by approximately 1000 kilometers. Research institutes included INIA (Agriculture), INFOR (Forestry), INFOP (Fisheries), CIMM/IM2 (Mining), Fundaccion Chile (Aqua-culture), EULA (Environmental), IMAR (Marine biology), COPA (Oceanogrphy), BIO-TECH and INDAP (Agriculture).

${ }^{7}$ This present investigation is based on a 1994, and subsequent follow up 2000-2002 and 2005, study in Africa and India. This longitudinal project focused on scientists working in the agricultural research sector and excluded those in the medical sciences. The sampling focus is a result of the overemphasis in research capacity of these developing regions brought on by the 1960s 'Green Revolution'. For comparison, agricultural scientists were oversampled in the Chilean context, while the medical sciences were excluded. Agriculture sciences made up 27 percent of the academic sample and 44 percent of the research institute sample. Natural scientists (biology, botany, oceanography) made up 25 percent of the academic respondents sampled and 35 percent of the research institute respondents sampled. The physical sciences (physics, chemistry and geology) made up 16 percent and 3 percent respectively. Social scientists (sociology, psychology, economics and political science) made up 14 percent and 4 percent respectively. Engineering sciences made up 17 percent and 12 percent respectively.
} 
DUQUE \& AL.: Internet practice and professional networks in Chilean science

while the average age of research institute scientists was 45 years old. ${ }^{8}$ Sixty-three percent of academic and 47 percent of research institute scientists held a PhD. Fifty percent of academic respondents held their highest degree from an institution located in a developed country, while this figure was only 40 percent for those working in research institutes. Finally, about one quarter of both the academic and research institute samples consisted of women scientists. In the following sub-section, we detail the main independent, dependent and control variables employed in this study.

\section{Measures}

It is important to note that among scientists in the North the primary motivation for adopting Internet technologies was for managing professional networks using email [ABEls \& AL., 1996; COVI \& KLING, 1996; LIEBSChER, 1997; KAMINER \& BRAunsteIn, 1998; VOORBIJ, 1999; BELL, 1999]. Throughout the global diffusion of the Internet though, measurements of adoption and use have been a contentious issue [ROBINSON, 2003; YNALVEZ \& AL., 2005]. Early studies in the North initially focused on simple access. As the developed world enjoyed Internet saturation, measures shifted to quality of connection - dial up versus broadband. Now that broadband has become dominant in most of the developed world, the discussion shifts to duration and diversity of use. Within many developing world scientific communities, though, simple access is still an open issue. Our past experience conducting research in Africa suggests that even in key sectors connectivity is expensive, slow, inconsistent and often unsustainable. Therefore, for our analyses of data from Africa and India [DUQUE \& AL., 2005; YNALVEZ \& AL., 2005], ready access and current use provided relevant measures for comparison. In contrast to these previous studies, measures of ready access and current use are not useful in Chile, since Chilean scientists are universally connected. ${ }^{9}$ This is credited in large part to three decades of digital network investments in universities and research institutes initiated during the dictatorship of Augusto Pinochet, coupled with Chile's consistent contact with international technology markets [DUQUE, 2007]. Therefore, to account for the Internet dimension in the Chilean context, the following three indicators were used in this study: (1) Year of adoption: a continuous variable recoded from the year in which the respondent reported first using email; (2) Intensity of use: an ordinal measure of hours in a typical week using email: $1=$ less than one hour, $2=$ one to five hours, $3=$ five to 10 hours; $4=10$ to 20 hours, $5=20$ hours or more; and (3) Diversity of use: a scale constructed using a sum of dichotomous $(1=\mathrm{yes} ; 0=$ no)

\footnotetext{
${ }^{8}$ About 10 percent of the academic and 24 percent of the research institute respondents were in their early career, while 46 percent of academic and 44 percent of research institute respondents were in their mid career. Forty-four percent of the academic and 33 percent of the research institute respondents were in their late career.

${ }^{9}$ Our data shows that 100 percent of Chilean scientists sampled enjoy a dedicated computer in their office and ready access to the Internet.
} 
responses to six questions regarding scientists' uses of email: (a) 'have you been a member of science and technology discussion group?;' (b) 'have you sent a message to such a discussion group?;' (c) 'have you discussed research with someone in a developed country?;' (d) 'have you started a professional relationship with someone you met on the Internet?;' (e) 'have you discussed a research proposal with funding agencies?;' and (f) 'have you submitted or reviewed manuscripts for journals?'.

We measure professional networks in six ways: (1) intra-organizational network; (2) inter-organizational network; (3) domestic network; (4) foreign network; (5) geographical network diversity; and (6) a new measure, collaboration range. Intraorganizational network is measured as the number of professional contacts within a respondent's parent organization with which they report working closely. Only other scientists, technicians, and doctoral students were included in these analyses. Because the distribution of this variable is positively skewed, we use a natural logarithm transformation in the regression analysis. Inter-organizational network is indicated by asking each respondent for his or her most important professional contacts (up to twelve) outside of their parent organization. Respondents were then asked to report the location of each inter-organizational professional contact, using up to six regions (local area, outside local area but within Chile, outside Chile but within Latin America, Europe, the United States, and Other). These variables were aggregated to compute measures of domestic and foreign contacts. Domestic network size is a count of reported professional inter-organizational contacts within Chile, while foreign network size is based on a count of all inter-organizational contacts outside of Chile.

Geographical diversity of professional networks takes into account the distinction between local and foreign ties, as measured by an index of qualitative variation (IQV). This variable is derived from the inter-organizational professional contacts list that distinguished between domestic and foreign ties. A value of " 1 " indicates that the professional network is 'balanced', with an even distribution of local and international ties, while a value of " 0 " indicates no symmetry at all, that is, either a respondent has all domestic or all foreign contacts in their professional network.

Since research collaborators also comprise a respondent's professional network, we introduce a measure indicating the geographical range of collaborations through which scientists pursue research. Collaboration range is a measure of the number of present collaborations out of three present projects reported by the respondent, weighted by the geographical location of the collaborators attached to these projects. We give greater weight to collaborators that are distant than to those that are near. In part, this reflects the greater prestige of foreign - particularly European and America - collaborations generally reported by scientists in our qualitative interviews [DUQUE, 2007]. However, globalization of science arguments generally refer to increasing frequency of collaborative work in far-flung areas as a key component of the shifts occurring in modern science. Respondents were asked to report on up to three main research 
DUQUE \& AL.: Internet practice and professional networks in Chilean science

projects, as well as the location of collaborators, if any, that were associated with these projects in up to four regions $(1=$ local, $2=$ outside the local area, but within Chile, $3=$ outside Chile but within Latin America, 4 = Europe, the United States, or other Canada, Australia, Asia, Africa). The range of the respondent's collaborations is measured by a count of total collaborators weighted by their geographical dispersion, extending from 0 (no collaborative projects) to a maximum of 54 (multiple collaborators across all four geographical categories for each of three collaborative projects reported). Because the distribution of this variable is positively skewed, this study employs a natural logarithm transformation in the regression analysis.

Control variables in this analysis include contextual (sector, location and field), demographic and educational factors as well as professional activities and awards. Academic scientists and research institute scientists labor within distinct organizational cultures that vary in terms of network size and reach, productivity, knowledge objectives and technology practices [COHEN \& AL., 1982; SMITH-DOERR, 2004]. For example, academic researchers often divide their time between research, teaching and administration. Research institute scientists often pursue research that leads to patents or immediate applications in the market. However, these contextual distinctions are being tested in the era of the global economy [ETZKOWITZ, 1989; NOWOTNY \& AL., 2001]. Sector is coded as a dummy variable with academic scientists as the reference group.

Location in the national research community has generally been an important factor in Chilean science. MULLIN \& AL. [2000] suggests that Chilean science is core-centric. Resources tend to flow to institutions and professionals located in the capital city, Santiago, at the expense of the periphery. This confirms BRADSHAW's [1987] contention that development often results in an urban bias of resource distribution. Location is measured as core $($ Santiago $)=1$, semi-periphery $($ Concepcion $)=2$, and periphery (Puerto Montt) $=3$. Research institutes were sampled from across all three regions, while the academic sample was concentrated in the semi-periphery, Concepcion. In the bivariate analysis therefore, the difference between locations reflects institutional variations more than regional, while in the regression analysis, differences reflect regional variations among scientists working in research institutions only.

Disciplines or scientific fields are characterized by different network characteristics [CRANE, 1971; COZZENS, 1990], information searching, communication [GARVEY \& AL., 1970; Ellis \& AL., 1993; LINDHOLM-ROMANTSCHUK \& WARNER, 1996] and processes of collaboration and publication [LABAND \& TOLLISON, 2000; MOODY, 2004; LEE \& BOZEMAN, 2005]. For example physicists tend to collaborate more than do social scientists, while engineers tend to publish less than do those in other fields. There is also indication that fields differ in information technology use [SCHAUDER, 1994; COHEN, 1996; WALSH \& BAYMA, 1996, LAZINGER \& AL., 1997; EASON \& AL., 1997; COSTA \& MeAdows, 2000; TALJA \& AL., 2004; FRY, 2004]. For example, scholars in biological sciences, agriculture and medicine have been more likely to depend on 
computer related technologies, followed by scholars in the physical sciences and engineering, then social sciences, law and business. Moreover, economists tended to be more technological oriented than are sociologists, while chemists, archaeologists, information scientists, and astronomers are more ready to exploit e-publishing than are scholars in the sports sciences, communication and cultural studies, law and history. To account for the contextual dimension of field, a series of dummy variables were created for agricultural, physical (physics, chemistry, geology), natural (biology, oceanography, botany) and social (sociology, psychology, economics) sciences with engineering sciences as the reference group.

Control variables also include demographic and educational dimensions. Female scientists are subject to unique cultural obstacles that limit both their ability to network and their productivity outcomes [XIE \& SHAUMAn, 2003; CAMPION \& SHrum, 2004; PALACKAL \& AL., 2006]. Moreover, ROGERS [1995] suggests that women tend to be late adopters of innovations, like the Internet, when compared with men. Gender is measured as $1=$ male, $0=$ female.

COLE \& COLE [1973] suggest that scientific behavior and productivity varies with age, with low productivity increasing through mid career and then dropping again late in the career cycle. This explains the expansion of a scientist's professional network as they progress in their career and a reduction of contacts toward retirement. But age is a factor in technology adoption as well. ROGERS [1995] suggests that younger cohorts are more likely to adopt innovations like Internet technologies, while DOTY \& AL. [1991], suggest that senior researchers may readily withdraw their participation from scholarly mailing lists if they do not see a benefit to information exchanges with junior or nonelite researchers. Age is measured in two ways depending on the type of analysis: a continuous variable for the regression analysis and an ordinal variable for the bivariate analysis - early career ( 25 to less than 35 years old), mid career ( 35 to less than 50 years old) and late career (50 years old and above).

Qualitative interviews in 2004 with Chilean researchers suggested the importance of seeking higher education abroad [DUQUE, 2007]. One motivation is that there are few $\mathrm{PhD}$ granting programs offered in Chile [KRAUSKOPF \& VERA, 1997; MULLIN \& AL., 2000]. Also, seeking an advanced degree in the North is a way for young scientists to improve their training, network with influential figures in their field and learn new techniques [DUQUE, 2007]. Since both location and level of education are important we include both factors in our models $-P h D(1=$ yes; $0=$ no), and highest degree from a developed country $(1=$ yes; $0=$ no $)$.

The importance of networking through association membership and annual conferences is fundamental in science across disciplines [CRANE, 1971; COZZENS, 1990]. Qualitative interviews conducted in Chile in 2004 suggested that the cost of attending conferences, and especially those abroad, was high while the perceived return was low. Internal politics of academic associations also discourage some Chilean 
DUQUE \& AL.: Internet practice and professional networks in Chilean science

scholars from participating [DUQUE, 2007]. Nonetheless, the majority of Chilean scientists sampled reported attending yearly conferences. In our study, this dimension is measured in the following two ways: reported membership in a professional association (yes $=1$, no $=0$ ); and the number of professional meetings attended in the past year. Because the distribution of this second variable is positively skewed, this study employs a natural logarithm transformation in the regression analyses.

Collaboration is often promoted within policy frameworks as a 'good' in itself [DUQUE \& AL., 2005]. The ability to share expertise, resources and comradeship often translates in greater productivity in some contexts. As a result, the World Bank Millennial project in conjunction with Chile's National Commission of Science and Technology Research (CONICYT), have promoted international collaboration as a strategy to increase scientific productivity [CONICYT, 2006]. Indications are that international collaboration among Chilean researchers has increased dramatically over the last half decade and it is generally credited for the jump in international publication and citations of Chilean scientists [HILL, 2004]. In this study, total collaborations are measured as a simple count of up to three projects that involve collaboration.

Finally, we control for the number of individual grant awards received and funding received as part of a larger project, both of which have long been identified as important to scientific work [COLE, 1992]. The latter was especially important to some Chilean scholars, who suggested conducting meaningful research necessitated funding through a collaborator in the exterior [DUQUE, 2007]. Because the distributions of these variables are positively skewed, this study employs a natural logarithm transformation in the regression analyses.

\section{Results}

We begin by examining the dimensions associated with network characteristics, including contextual, demographic and Internet factors. Next we examine the correlation between domestic and international links. Finally, to examine the effect of the Internet on professional networks, paired regression models present the relationships between professional networks and contextual, demographic and professional factors, with and without controls for Internet use.

Table 1 presents differences in the size and diversity of professional networks across eight dimensions. T-tests (for dichotomies) and ANOVA post hoc means comparisons test (for multiple categories) were used to determine significant differences. Possession of a doctorate [line 17] and having been trained in a developed country [line 19] are associated with larger external (international) networks and greater collaboration diversity, but those without a $\mathrm{PhD}$ have larger local networks. Age [lines 13-15] demonstrates a curvilinear relationship with foreign linkages and collaboration range. 
DUQUE \& AL.: Internet practice and professional networks in Chilean science

Table 1. Means of professional network measures by contextual and social characteristics

\begin{tabular}{|c|c|c|c|c|c|c|c|}
\hline & 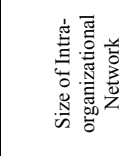 & 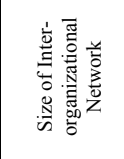 & 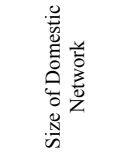 & 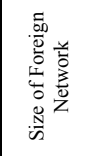 & 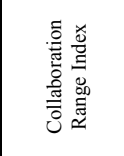 & 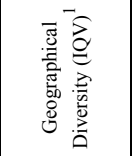 & \\
\hline & 1 & 2 & 3 & 4 & 5 & 6 & \\
\hline & Mean & Mean & Mean & Mean & Mean & Mean & $\mathrm{N}=337$ \\
\hline \multicolumn{8}{|l|}{ Location } \\
\hline 1. Santiago ${ }^{\mathrm{a}}$ & 10.0 & 6.2 & $4.2^{\mathrm{b}^{* *}}$ & 1.9 & 6.4 & 0.45 & $11 \%$ \\
\hline 2. Concepcion ${ }^{\mathrm{b}}$ & 8.1 & 5.7 & 3.1 & 2.6 & 6.9 & $0.58^{\mathrm{a} * \mathrm{c}^{* *}}$ & $77 \%$ \\
\hline 3. Puerto Montt ${ }^{\mathrm{C}}$ & 10.3 & $7.0^{b^{* *}}$ & $4.7^{\mathrm{b}^{* * *}}$ & 2.2 & $10.4^{\mathrm{a}^{* *} \mathrm{~b}^{* * *}}$ & 0.43 & $12 \%$ \\
\hline \multicolumn{8}{|l|}{ Sector } \\
\hline 4. Universities & 6.5 & 5.7 & 3.1 & 2.6 & 6.1 & $0.59 * *$ & $62 \%$ \\
\hline 5. Research Institute & $12.0^{* * * *}$ & $6.4 * *$ & $4.1^{* * * *}$ & 2.3 & $9.3^{* * *}$ & 0.48 & $38 \%$ \\
\hline \multicolumn{8}{|l|}{ Field } \\
\hline 6. Agricultural Sciences ${ }^{\mathrm{a}}$ & $10.8^{\mathrm{bd}^{* * *} \mathrm{e}^{* *}}$ & $6.6^{\mathrm{d}^{* * *} \mathrm{be}^{* *}}$ & $4.2^{\mathrm{b}^{* * *}} \mathrm{~cd} \mathrm{~d}^{* *}$ & 2.4 & $8.0^{\mathrm{d}^{* *}}$ & 0.54 & $34 \%$ \\
\hline 7. Physical Sciences ${ }^{b}$ & 6.6 & 5.4 & 2.6 & 2.8 & 7.1 & $0.69^{\mathrm{ac}^{*} \mathrm{de} \mathrm{e}^{* * *}}$ & $11 \%$ \\
\hline 8. Natural Sciences ${ }^{\mathrm{c}}$ & $8.4^{\mathrm{d}^{* * *}}$ & 6.0 & 3.2 & $2.8^{\mathrm{e}^{* *}}$ & $7.9^{\mathrm{d}^{* *}}$ & 0.54 & $29 \%$ \\
\hline 9. Engineering Sciences ${ }^{\mathrm{d}}$ & 5.4 & 5.2 & 3.1 & 2.2 & 5.5 & 0.50 & $10 \%$ \\
\hline 10. Social Sciences ${ }^{\mathrm{e}}$ & 8.0 & 5.3 & 3.3 & 1.9 & 6.6 & 0.47 & $16 \%$ \\
\hline \multicolumn{8}{|l|}{$\operatorname{Sex}$} \\
\hline 11. Female & 7.4 & 5.3 & 3.1 & 2.2 & 7.2 & 0.49 & $24 \%$ \\
\hline 12. Male & 8.9 & $6.1^{* *}$ & 3.5 & 2.6 & 7.4 & 0.57 & $76 \%$ \\
\hline \multicolumn{8}{|l|}{ Age } \\
\hline 13. 25 years to less than 35 years ${ }^{a}$ & 7.3 & 5.7 & 4.0 & 1.6 & 5.8 & 0.48 & $15 \%$ \\
\hline 14. 35 years to less than 50 years b & 8.4 & 5.7 & 2.9 & $2.7^{\mathrm{a}^{* * *}}$ & $8.3^{\mathrm{a}^{* *}}$ & 0.59 & $45 \%$ \\
\hline 15.50 years and above $\mathrm{c}^{\mathrm{c}}$ & 9.0 & 6.3 & 3.8 & $2.6^{\mathrm{a}^{* * * *}}$ & 6.8 & 0.52 & $40 \%$ \\
\hline \multicolumn{8}{|l|}{ Education } \\
\hline 16. Non-PhD & 9.4 & 6.0 & $42^{* * * *}$ & 1.8 & 5.9 & 0.48 & $43 \%$ \\
\hline 17. $\mathrm{PhD}$ & 7.9 & 5.9 & 2.9 & $3.0^{* * * *}$ & $8.3^{* * *}$ & $57^{* * *}$ & $57 \%$ \\
\hline \multicolumn{8}{|l|}{ High degree from developed country } \\
\hline 18. No & 8.3 & 5.6 & 3.6 & 2.0 & 6.3 & 0.42 & $54 \%$ \\
\hline 19. Yes & 8.8 & $6.3^{* * *}$ & 5.3 & $3 \mathrm{j}^{* * * *}$ & $8.6^{* * *}$ & $0.64 * * *$ & $46 \%$ \\
\hline \multicolumn{8}{|l|}{ Member of Prof. Organization } \\
\hline 20 . No & 9.0 & 5.6 & 3.5 & 2.1 & 7.5 & 0.47 & $24 \%$ \\
\hline 21. Yes & 8.4 & 6.0 & 3.3 & 2.6 & 7.3 & 0.64 & $76 \%$ \\
\hline
\end{tabular}

$* * * \mathrm{p}<0.01, * * \mathrm{p}<0.05, * \mathrm{p}<0.1$. Significant differences reflect a one-way Anova LSD post ad hoc means comparison test. Letters [a,b,c,d,e] followed by level of significance [*,**,***] distinguish differences between variables with more than two attributes. For example, on average scientists located in Puerto Montt [line 3] have significantly [ $p<0.05$ ] larger external networks [column 2] than those located in Conception [line 2], 7.0 and 5.7 respectively.

Mid career professionals generally enjoy an advantage over early and late career scientists, a relationship that generally reflects findings on age and professional careers in the North [COLE \& COLE, 1973]. Aside from geographical diversity, scientists working in research institutes [line 5] have an advantage in domestic network size and range over those working in academic departments. Academic scientists must publish in high impact journals for career advancement and gatekeepers abroad mediate many of 
DUQUE \& AL.: Internet practice and professional networks in Chilean science

these journals. ${ }^{10}$ As a result, academic scientists may rely more on contacts abroad than do research institute scientists.

Considering field, agricultural scientists [line 6] have larger organizational and domestic networks, but physical scientists [line 7] display greater geographical diversity. This is understandable since Chile's export economy and research funding emphasize the agricultural sector, while other fields more often rely on contacts abroad for collaboration, funding and new ideas. Table 1 demonstrates that while there is an advantage to being in the core (Santiago) for its larger domestic networks, diversity favors those in the semi-periphery and periphery [lines 1-3]. This may be explained by the number of international research resources dedicated to the booming aquaculture industry in the south as well as the study of its detrimental socio-environmental consequences [DUQUE, 2007].

There is also little variability in network size and diversity by gender [line 11-12]. Males have an advantage in the number of contacts outside their home organization, though. While these bivariate findings seem to suggest that in the digital age Chilean female scientists enjoy more equal network access to contacts that can provide them support, the multivariate analyses that follow paint a more complex picture. Before turning to the regression models though, it is important at this point to determine the relationship between local and foreign contacts among Chilean scientists.

Previous research has shown an inverse relationship between domestic and international ties among developing world scientists [SHRUM \& CAMPION, 1998], and our data reveals a similar association. The Pearson correlation coefficient between the number of local and foreign contacts is -0.31 , statistically significant at the 0.05 level: Chilean researchers with more domestic contacts tend to have fewer foreign colleagues. Conversely, those researchers with many foreign contacts report fewer domestic relationships. The question is, does this inverse relationship in the Internet age determine that the Chilean scientific community is locally disjointed and dependent upon the North - the affliction process? To address this, we now consider the most significant factors associated with domestic oriented, foreign oriented and geographically balanced network profiles.

Table 2 presents our main findings on the correlates of scientific networks in Chile, with and without dimensions of Internet practice. Paired regression models for network size and diversity first consider the effects of contextual, demographic and professional variables (odd numbered models in columns 1, 3, 5, 7, 9 and 11). Even numbered models (columns 2, 4, 6, 8, 10 and 12) introduce three Internet factors: (1) email experience, as measured by the number of years of use, (2) extent of usage, as measured

\footnotetext{
${ }^{10}$ In the qualitative phase of the study, academic researchers repeatedly underscored the necessity to publish in high impact ISI journals for career advancement. Few of these journals are published in Spanish or are located outside the North. Thus, career advancement for academic scholars often passes through gatekeepers abroad. In contrast, research institute scientists placed more emphasis on grant and report writing, extension work and the pursuit of patents for their innovations [DUQUE, 2007].
} 
by the hours of email use in a typical week, and (3) diversity of use, as indicated by the variety of online activities reported by the respondent. Because their distributions are positively skewed, we employ natural logarithmic transformations for two dependent variables (self-reported number of 'intra-organizational contacts' and the 'collaboration range index') and three independent variables (self-reported number of 'conferences attended', 'individual awards' and 'project awards').

Column 1 in Table 2 provides standardized regression coefficients and levels of significance for a model that explains almost 20 percent of the variation in the size of intra-organizational networks. This first model shows that male scientists in research institutes, in the fields of agriculture, natural sciences, and social sciences have significantly larger intra-organizational network, especially when they collaborate often.

Table 2. Regression of context, background, and internet use on network size, prestige, and diversity

\begin{tabular}{|c|c|c|c|c|c|c|c|c|c|c|c|c|}
\hline & \multicolumn{2}{|c|}{ 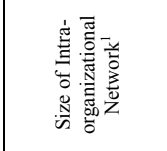 } & \multicolumn{2}{|c|}{ 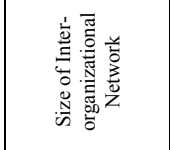 } & \multicolumn{2}{|c|}{ 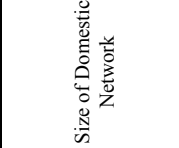 } & \multicolumn{2}{|c|}{ 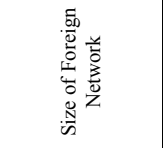 } & \multicolumn{2}{|c|}{ 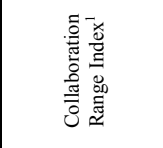 } & \multicolumn{2}{|c|}{ 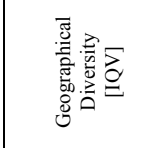 } \\
\hline & 1 & 2 & 3 & 4 & 5 & 6 & 7 & 8 & 9 & 10 & 11 & 12 \\
\hline \multicolumn{13}{|l|}{ Context } \\
\hline 1. Location & 0.050 & 0.058 & 0.051 & 0.055 & 0.066 & 0.055 & -0.008 & 0.012 & 0.068 & $0.086^{*}$ & -0.028 & -0.012 \\
\hline 2. Research institute & $0.224 * * *$ & $0.215^{* * *}$ & 0.013 & -0.035 & 0.065 & 0.058 & -0.073 & $-0.130 * *$ & $0.202 * * *$ & $0.203 * * *$ & $-0.133 * *$ & $-0.158 * *$ \\
\hline 3. Agricultural sciences & $0.253^{* * *}$ & $0.278^{* * *}$ & 0.112 & 0.099 & 0.106 & 0.068 & 0.004 & 0.033 & $0.163^{* * *}$ & $0.217 * * *$ & 0.065 & 0.077 \\
\hline 4. Physical sciences & 0.038 & 0.040 & 0.012 & 0.005 & -0.017 & -0.021 & 0.026 & 0.022 & 0.021 & 0.026 & $0.126^{*}$ & $0.121 *$ \\
\hline 5. Natural sciences & $0.144 *$ & $0.161^{* *}$ & 0.052 & 0.053 & -0.014 & -0.034 & 0.081 & 0.107 & 0.072 & 0.095 & 0.06 & 0.0602 \\
\hline 6. Social Sciences & $0.130 * *$ & $0.137 * *$ & -0.014 & -0.028 & 0.016 & 0.004 & -0.049 & -0.053 & $0.113^{*}$ & $0.127^{* * *}$ & -0.004 & -0.010 \\
\hline \multicolumn{13}{|l|}{ Background \& Education } \\
\hline 7. Gender [male] & $0.089^{*}$ & $0.090^{*}$ & $0.111 * *$ & $0.116^{* *}$ & $0.111 * *$ & $0.116^{* *}$ & 0.002 & 0.001 & 0.017 & 0.911 & 0.028 & 0.023 \\
\hline 8 Age [years] & 0.046 & 0.048 & 0.021 & 0.043 & -0.028 & -0.028 & 0.056 & 0.085 & -0.075 & 0.191 & $-0.137 * *$ & $-0.123 * *$ \\
\hline 9. $\mathrm{PhD}$ & 0.049 & 0.047 & $-0.121 * *$ & $-0.134 * *$ & $-0.253 * * *$ & $-0.239 * * *$ & $0.156^{* * *}$ & $0.119^{*}$ & 0.041 & 0.899 & $0.135^{* *}$ & 0.103 \\
\hline $\begin{array}{l}\text { 10. Degree from } \\
\text { a developed country }\end{array}$ & -0.024 & -0.033 & $0.133 * *$ & $0.121^{* *}$ & 0.016 & 0.031 & $0.174^{* * *}$ & $0.140 * *$ & $0.123 * *$ & 0.108 & $0.156 * *$ & $0.135 * *$ \\
\hline \multicolumn{13}{|c|}{ Professional Activities and Awards } \\
\hline $\begin{array}{l}\text { 11. Number of conferences } \\
\text { attended }\end{array}$ & 0.044 & 0.035 & $0.122 * *$ & 0.088 & 0.054 & 0.066 & $0.100^{*}$ & 0.039 & $0.116^{* *}$ & 0.084 & 0.031 & 0.005 \\
\hline 12. Total Collaborations & $0.095^{*}$ & 0.094 & $0.129 * *$ & $0.153^{* * * *}$ & 0.005 & 0.022 & $0.152 * *$ & $0.162 * *$ & $\mathrm{~N} / \mathrm{A}$ & N/A & -0.005 & -0.025 \\
\hline 13. Individual Awards ${ }^{1}$ & $0.096^{*}$ & 0.086 & $0.130 * *$ & $0.115^{* *}$ & $0.122 * *$ & $0.141^{* *}$ & 0.041 & -0.005 & $0.109 * *$ & 0.067 & $0.129 * *$ & $0.101^{*}$ \\
\hline 14. Grants ${ }^{1}$ & $0.101^{*}$ & $0.095^{*}$ & $0.151 * * * \mid$ & $0.131 * *$ & $0.216 * * *$ & $0.224^{* * *}$ & -0.065 & $-0.104 *$ & $0.260^{* * * *}$ & $0.234 * * *$ & 0.047 & 0.028 \\
\hline \multicolumn{13}{|l|}{ Internet Factors } \\
\hline $\begin{array}{l}\text { 15. Number of years } \\
\text { using email }\end{array}$ & & 0.043 & & $-0.109^{*}$ & & $-0 . \mathbf{1 2 0}^{* *}$ & & 0.002 & & $0.194 * * *$ & & 0.012 \\
\hline $\begin{array}{l}\text { 16. Hours using email } \\
\text { in a typical week }\end{array}$ & & 0.074 & & $0.101^{*}$ & & -0.032 & & $0.174 * * * 4$ & & 0.044 & & 0.055 \\
\hline 17. Email use diversity & & -0.010 & & $0.134^{* *}$ & & 0.003 & & $0.187 * * *$ & & 0.052 & & $0.149 * *$ \\
\hline 18. $\mathrm{R}^{2}$ & 0.196 & 0.202 & 0.171 & 0.201 & 0.167 & 0.181 & 0.154 & 0.219 & 0.235 & 0.273 & 0.128 & 0.149 \\
\hline 19. $\mathrm{N}$ & 326 & 325 & 326 & 325 & 326 & 325 & 326 & 325 & 326 & 325 & 322 & 321 \\
\hline
\end{tabular}

$* * * \mathrm{p}<0.01, * * \mathrm{p}<0.05, * \mathrm{p}<0.1$

1. Variable is expressed as a logarithmic transformation.

Note: There are no coefficients for the intersections of Total Collaborations [line 12] and Collaboration Range [columns $9 \& 10]$. These variables are derived from the same measure. 
DUQUE \& AL.: Internet practice and professional networks in Chilean science

Most of these associations hold with controls for Internet use (Model 2), no dimension of which has any significant association with the size of intra-organizational networks. This is unsurprising, and suggests that internal organizational networks continue to be dominated by face-to-face interaction, whether or not scientists are heavy email users.

Models 3 and 4 predict the size of scientists' inter-organizational networks, without regard to the location of the contacts. Unlike internal networks, organizational location (university department or research institute) and scientific field make no difference to the overall size of networks. The gender effect remains significant $(b=0.111)$, favoring men. Holding a PhD is significant, but surprisingly, the effect is negative $(b=-0.121)$, with $\mathrm{PhD}$ holders having smaller networks overall than non-holders. Acquiring a high degree from a developed country is significant and positive $(b=0.133)$. These findings on the relationship between education and network size show that the bivariate associations in Table 1 (lines 16-19) remain significant in multivariate models with a variety of controls. Close to half of $\mathrm{PhDs}$ are acquired outside Chile, yet higher degrees themselves are not associated with larger networks. Attending conferences $(b=0.122)$, collaboration frequency $(b=0.129)$, and both individual $(b=0.130)$ and project grant awards $(b=0.151)$ are significantly related with larger inter-organizational networks. All except one of these significant relationships hold when the study introduces Internet factors in Model 4. Attending conferences is no longer a significant predictor of inter-organizational networks size, but all three Internet dimensions emerge as significant. Extent of use and diversity of use are associated with larger networks, while 'years of experience' is associated with smaller networks, suggesting a kind of 'saturation' or 'novelty' effect.

Overall network size is less interesting for our purposes than its two components, domestic and international networks. The paradoxical findings on higher education and years of Internet experience are clarified through the analysis in Models 5 through 8 , which directly address one of the major issues of this paper: How is Internet use associated with the location of professional contacts for developing world scientists? Past studies, largely in the pre-Internet era, showed that developing world scientists are isolated or that they are predominantly local in character [GAILLARD, 1991]. One study, conducted in 2000, showed relatively low levels of foreign contacts among researchers in India [DUQUE \& AL., 2005]. As we mention earlier, we statistically concluded that there is an inverse relationship between domestic and foreign contacts in Chile that mirrors past studies [SHRUM \& CAMPION, 1998]. To some extent, Chile reflects a developing world science network configuration.

Models 5 through 8 show virtually no field or organizational sector affects on the size of networks, relatively strong educational effects, and Internet effects for foreign but not domestic networks. Models 5 and 6 indicate a profile for the locally oriented scientist. In the first of these two models, males, non- $\mathrm{PhD}$ holders, grants and awards are associated with larger domestic networks. The findings on gender and education are intuitive in the Chilean context, where traditional gender roles still apply and about half 
of Chilean scientists pursue a $\mathrm{PhD}$ abroad. When Internet controls are included in Model 6, these three predictors remain significant, while years of Internet experience is significant and negative. The longer a scientist has used the Internet, the smaller his or her Chilean network.

The size of foreign networks is predicted in Models 7 and 8, and reflects consistent findings with or without Internet controls. While $\mathrm{PhD}$ scientists have smaller domestic networks, Models 7 and 8 show that they have larger international networks $(b=0.156 / 0.119)$, and as we would expect, larger networks are associated with a high degree acquired in a developed country $(b=0.174 / 0.140)$. Collaboration frequency is highly significant, while attending professional conferences $(b=0.100)$ is marginally so, but only in Model 7. When Internet controls are introduced in Model 8, sector emerges as significant $(b=-0.130)$ : academic scientists tend to have larger foreign networks than scientists at research institutes. However, the two most important predictors of the size of international networks are the extent and diversity of email use.

In Models 9 and 10, our index of collaboration range is regressed on the same set of control variables. It is impacted by organizational sector, working in a research institute $(b=0.202)$, and field, agricultural $(b=0.163)$ and social sciences $(b=0.113)$, as well as location of highest degree $(b=0.156)$, professional meetings attendance $(b=0.116)$, individual awards $(b=0.109)$, and grants $(b=0.260)$. Training in developing countries and attending more conferences provide opportunities for researchers to create a global presence. Enjoying more grant awards translates into resources with which to attend international conferences and attract collaborators.

When Internet controls are introduced in Model 10, field and sector remain significant but degrees from developed countries and conferences are no longer associated with collaboration range. Instead, grants and Internet experience are the important predictors. The dependent variable here, collaboration range, is weighted to reflect international collaboration. It appears from Table 2 that wide ranging foreign collaborations are developed through years of Internet use, and the actual time spent on the Internet is less important.

The final models predict the geographical diversity of networks, again using the distinction between local and international ties, but this time predicting balanced networks, where a network is balanced to the extent that the measure approaches a value of one. It is unbalanced as it approaches 0 , consisting of all domestic or all foreign contacts. Positive coefficients in models 11 and 12 indicate balance, while negative coefficients indicate concentration of ties either domestically or internationally. Models 11 and 12 are the only models in which age is important, with younger scientists more likely to exhibit balanced networks than older scientists. Holding a high degree from a developed country as well as individual grant awards are also significantly associated with a more geographically symmetrical network profile, without and with Internet controls. However, possession of a $\mathrm{PhD}$ is no longer significant with controls for 
DUQUE \& AL.: Internet practice and professional networks in Chilean science

Internet use. Diversity of email use is the single dimension that translates to a balanced geographical network.

Looking across columns of Table 2, there are three models in which the number of conferences attended (row 11) has a statistically significant relationship with network size and collaboration. However, in each of these cases, when Internet use is controlled the association disappears, suggesting that some aspects of Internet use may be reducing the importance of international meetings. For instance, comparing columns 9 and 10 of row 11, it is not the intensity of use but only length of time email has been used that predicts wide-ranging collaboration, and conferences seem not to affect this once years of email use is controlled. This supports a functional equivalence argument with respect to Internet technologies [GERSHUNY, 2002], which may explain our second and third important findings: larger foreign networks are associated with more intensive and diverse email use, and there is symmetry in terms of foreign networks, diverse networks and collaboration range along regional, gender and age dimensions.

\section{Discussion}

As contrasted with the relatively low Internet access and use reported in prior studies of developing regions, Chileans scientists are digitally well connected. But in social network terms, the results are more complex. It is imperative that we consider this complexity in joining any discussion of 'isolated' or 'disarticulated' researchers with respect to 'science \& technology' for development [SHRUM \& CAMPION, 1998; SAGASTI \& AL., 2003]. The most consistent predictors of network profiles concluded in our study are Internet experience and use. In five of six models presented, Internet variables are significantly associated with network measures. The size of intraorganizational networks, though, is not associated with Internet factors, indicating that traditional modes of interaction (whether face-to-face or telephone) remain dominant at the local level of networking. However, addressing the major issue of this paper - the relationship between domestic and foreign networks and the equitable distribution of network resources in the Internet era - we found:

1. A significant inverse correlation with respect to local and international linkages.

2. Internet factors are positively associated with foreign contacts, but negatively for domestic ties, suggesting that the Internet provides a means for foreign networking, but not necessarily local networking.

3. There is a positive association between email use diversity and geo-graphical network diversity suggesting that the Internet in Chile is also acting as a valuable conduit for symmetrical networks.

4. The Internet may be replacing past modes of networking.

5. In the Internet era, there is an equitable distribution of network resources by region, gender and age. 
Findings one and two suggest an 'affliction' process. The first echoes the inverse local/global network configuration observed in other developing regions that is often associated with a locally disjointed and exogenously dependent scientific community [CAMPION \& SHRUM, 2004; SAGASTI \& AL., 2003]. The second cautions 'e-science for development' programs, unless the negative impact of Internet experience on local ties proves to be temporary. We were somewhat surprised that email experience is negatively associated with both local and total network size. Even controlling for age, years of Internet use is associated with small domestic networks. This suggests that lengthy Internet use has drawn researchers away from the local and toward the international scientific arena. We take no position on whether this phenomenon is good or bad, since our Chilean data is cross-sectional and we may be seeing what is essentially a passing moment in the history of Internet adoption and early use. However, since Internet experience is also positively associated with greater collaboration range, this is likely to be a matter that warrants careful attention in the future.

In addition, the extent and diversity of Internet use are both significantly and positively associated with international network size. This supports past research that suggests Internet technologies are geographically extending scientific linkages [SPROULL \& KIESLER, 1991; Wellman \& AL., 1996; WALSH \& BYMA, 1996]. Should the Internet though be promoting foreign ties at the expense of local ties, strongly suggests the kind of important vulnerability associated with the adoption and use of Internet technologies that have been argued by others [DAVIDSON \& AL., 2003; KENNY, 2006].

The remaining findings, however, suggests that the overall story is complex. First, past research contends that some combination of weak ties (access to new ideas) and strong ties (access to complex knowledge) is beneficial, especially in determining organizational outcomes [UzZI, 1996]. In the Chilean context of this study, a balanced local and global network configuration is associated with diversity of email usages and this suggests an 'elixir' process involving Internet technologies. Moreover, in our model of collaboration range, Internet controls eliminate the effect of acquiring the highest degree from a developed country. In the model of geographical diversity, they cancel the affect of the PhD. These findings support a functional equivalence argument [GERSHUNY, 2002], suggesting that the Internet may be efficiently replacing past modes of networking. This is not a minor finding in a region that reports ambivalence in attending international conferences, due to expense and lack of relevance [DUQUE, 2007]. This also suggests an 'elixir' outcome.

Concerning the fifth finding, the geo-social divides in the digital age, Muluins \& AL. [2000] suggested that there is an asymmetrical relationship in resources in the Chilean research sector. Research organizations in the capital city of Santiago, the core, enjoy a greater advantage in resources when compared to organizations farther from the capital city (the semi periphery and periphery). Even though this tends to reflect the historical tendency towards urban bias in the concentration and use of development 
DUQUE \& AL.: Internet practice and professional networks in Chilean science

resources [BRADSHAW, 1987], the data in our study suggest a different interpretation in the Internet era. The core is not necessarily the most opportune place to be in Chile, especially if a scientist is working within the research institute sector. Since the global diffusion of the Internet, such geographical centrality is challenged. This echoes CASTELLS' [2000] view that magnifies the importance of connected global nodes, just as it contradicts FINHOLT's [2004] suggestion that the Internet does not necessarily provide scientists at the margins access to 'invisible colleges'. In Chile, the digital networking of the national research sector during the Pinochet dictatorship, when combined with the recent concentration of the global aquaculture industry in the periphery, is consistent with this "networked society" contention. ${ }^{11}$

\section{References}

ABEls, E. G., LiEBSCHER, P., DENMAN D. (1996), Factors that influence the use of electronic networks by science and engineering faculty at small institutions, Journal of the American Society for Information Science, 47 : 146-158.

ADAM, L., WoOD, F. (1999), An investigation of the impact of information and communication technologies in Sub-Saharan Africa, Journal of Information Science, 25 : 307-318.

BELL, A. (1999), The impact of electronic information on the academic research community, New Review of Academic Librarianship, $3: 1-24$.

BouAs, K. S., Arrow, H. (1995-1996), The development of group identity in computer and face-to-face groups with membership change, computer supported cooperative work, Computer Supported Cooperative Work, 4 : 153-78.

Borgatti, S. P., Jones, C. (1998), Network measures of social capital, Connections, 21 : 27-36.

BRADSHAW, Y. (1987), Urbanization and underdevelopment: A global study of modernization, urban bias, and economic dependency, American Sociological Review, 52 : 224-239.

Brown, S. S., Duguid, P. T. (2000), The Social Life of Information. Boston: Harvard Business School Press.

BuRT, R. S. (1992), Structural Holes. Cambridge: Harvard University Press.

CAMPION, P., Shrum, S. (2004), Gender and science in developing areas, Science, Technology \& Human Values, $29: 459-85$.

Castells, M. (2000), The Rise of the Network Society, 2nd Edition. Oxford: Blackwell Publishing.

COHEN, J. (1996), Computer mediated communication and publication productivity among faculty, Internet Research : Electronic Networking Applications and Policy, 6 (2-3) : 41-63.

Cohen, P. B, Kruse, R. J., ANBAR, M. (1982), The social structure of scientific research teams, The Pacific Sociological Review, $25: 205-232$.

Cole, J. R., COLE, S. (1973), Social Stratification in Science. Chicago: University of Chicago Press.

COLE, S. (1992), Making Science : Between Nature and Society. Cambridge: Harvard University Press.

CONICYT (2006), Chile's National Commission of Science and Technology Research : http://www.conicyt.cl/

COSTA, S., MEADOwS, J. (2000), The impact of computer usage on scholarly communication among social scientists, Journal of Information Science, 26 (4) : 255-262.

Covi, L., KLING, R. (1996), Organizational dimensions of effective digital library use : closed rational and open natural systems models, Journal of the American Society for Information Science, 47 (9) : 672-689.

Cozzens, S. E. (1990), Autonomy and Power in Science. In: S. CozzENS, T. GuIEYN (Eds), Theories of Science in Society, Bloomington: Indiana University Press, pp. 164-184.

${ }^{11}$ Since this present study did not include academic departments outside of Concepcion, future research should test if access to professional networks by region, gender and age in the university sector coincides with the symmetry we found among research institute scientists. 
DUQUE \& AL.: Internet practice and professional networks in Chilean science

CRANE, D. (1971), Transnational networks in basic science, International Organization, $25: 585-601$.

DAVIDSON, T., SOORYAMOORTHY, R., SHRUM, W. (2003), Kerala connections: will the internet affect science in developing areas? In: B. Wellman, C. HAYTHORNTHWAITE (Eds), The Internet in Everyday Life, Oxford: Blackwell, pp. 496-519.

DeL RoY, O. (1997), The African challenge : Internet, networking and connectivity activities in a developing environment, Third World Quarterly, $18: 88-98$.

De Moya-Anegón, F, Chinchilla-Rodríguez, Z., Vargas-Quesada, B., Corera-Álvarez, E., José MuÑoz-FernándeZ, F., GonZÁlez-Molina, A., Herrero-Solana, V. (2007), Coverage analysis of Scopus : a journal metric approach, Scientometrics, 73 (1) : 53-78.

Dimaggio, P., Hargittai, E., Neuman, R., Robinson, J. (2001), Social implications of the internet, Annual Review of Sociology, 27 : 307-36.

Doty, P., Bishop, A. P., MCCLURE, C. R. (1991), Scientific norms and the use of electronic research networks. ASIS'91: Proceedings of the 54th Annual Meeting of the American Society for Information Science, 24-38.

DuQue, R. B. (2007), Global internet research : Internet golpe in Chile. In: W. SHRUM, K. BENSON, W. BiJKeR, K. BrunNSTEIN (Eds), Past, Present and Future of Research in the Information Society. New York: Springer Books, pp. 198-206.

Duque, R. B., Ynalvez, M., Sooryamoorthy, R., Mbatia, P., Dzorgbo, D., Shrum, S. (2005), Collaboration paradox : Scientific productivity, the internet, and problems of research in developing areas, Social Studies of Science, 35 : 755-785.

Eason, E., Carter, C, Harker, S., Pomfrett, S., Phillips, K., Richardson, J. (1997), A Comparative Analysis of the Role of Multi-Media Electronic Journals in Scholarly Disciplines: Final Report. Loughborough: HUSAT Research Institute. Department of Human Sciences, Loughborough University. URL: http://www.ukoln.ac.uk/services/elib/papers/tavistock/eason/eason.html

EHIKHAMENOR, F. A. (2003), Internet resources and productivity in scientific research in Nigerian universities, Journal of Information Science, $29: 107-15$.

Ellis, D., Cox, D., HAll. K. (1993), A comparison of information seeking patterns of researchers in the physical and social sciences, Journal of Documentation, 49 (4) : 356-369.

EngelHard, R. (1999), State of the Art of the Opportunities Offered by New ICTs in the Building of Cooperation Programmes, A contribution to the European Forum on ARD of 7-8 April 1999, Wageningen, The Netherlands. URL: http://www.contactivity.com/en/content/download/238/1442/file /Natura_ICT\%20in\%20ARD_ed_rtf[1].pdf

ESCOBAR, A. (1994), Welcome to cyberia : notes on the anthropology of cyberculture, Current Anthropology, $35: 211-31$

EsCoBAR, A. (1995), Encountering Development: The Making and Unmaking of the Third World. Princeton: Princeton University Press.

EтZKOwitZ, H. (1989). Entrepreneurial science in the academy: a case of the transformation of norms, Social Problems, 36 (1) : 14-29.

FinHOLT, T., OLSON, G. (1997), From laboratories to collaboratories : A new organizational form for scientific collaboration, Psychological Science, $8: 28-36$.

Finholt, T. (2002), Collaboratories, Annual Review of Information Science and Technology, 36 : 73-107.

FRY, J. (2004), The cultural shaping of ICTs within academic fields : Corpus-based linguistics as a case study, Literary and Linguistic Computing, 19 (3) : 303-319.

Fuchs, C. (2008), Internet and Society : Social Theory in The Information Age. New York: Rougtledge.

GAILLARD, J. (1991), Scientists in the Third World. Lexington: University of Kentucky Press.

Galimberti, C., Ignazi, S., Vercesi P., Riva, G. (2001), Communication and cooperation in networked environments : an experimental analysis, Cyberpsychology and Behavior, 4 : 131-146.

Garvey, W. D., Lin, N., Nelson, C. E. (1970), Communication in the physical and the social sciences, Science, 170 (3963) : 1166-1173.

GERSHUNY, J. (2002), Social leisure and home IT, a time-diary approach, IT \& Society, 1: 54-72.

GeREFFI, G. (1989), Rethinking development theory : insights from East Asia and Latin America, Sociological Forum, 4 : 505-534.

GIBBS, W. W. (1995), Lost science in the Third World, Scientific America, 273 : 92-99. 
DUQUE \& AL.: Internet practice and professional networks in Chilean science

GRANOVETTER, M. (1973), The strength of weak ties, American Journal of Sociology, 78 : 1360-1380.

HANSEN, M. T. (1999), The search-transfer problem : the role of weak ties in sharing knowledge across organization subunits, Administrative Science Quarterly, 44 : 82-111.

Hedley, A. (1999), The information age : apartheid, cultural imperialism, or global village? Social Science Computer Review, 17 : 78-87.

HiLl, D. (2004), Latin America Shows Rapid Rise in S\&E Articles, Info Brief : Science Resource Statistics. Report for Directorate of Social, Behavioral, and Economic Sciences, National Science Foundation, 04-336.

Hine, C. M. (2006) (Ed), New Infrastructures for Knowledge Production: Understanding E-Science. London: Information Science Publishing.

Holmgren, M., Schnitzer, S. A. (2004), Science on the rise in developing countries. PLoS Biol, 2 (1) : URL: doi:10.1371/journal.pbio.0020001

HuAng, H. (2007), Re-examining Academic-Industrial Collaboration : The Impacts of Information Communication Technologies on Knowledge Sharing and Innovation. In: W. SHRUM, K. BENSON, W. Bijker, K. Brunnstein (Eds), Past, Present and Future of Research in the Information Society. New York: Springer Books, pp. 110-112.

JimBA, S. W., ATINMO M. (2000), The influence of information technology access on agricultural research in Nigeria. Internet Research-Electronic Networking Applications and Policy, $10: 63-71$.

KAMINER, N., Braunstein, Y. (1998), Bibliometric analysis of the impact of internet use on scholarly productivity, Journal of the American Society for Information Science, 49 (8) : 720-730.

KENNY, C. (2006), Overselling the Web? Development and the Internet. Boulder: Lynne Rienner Publishers.

Koku, E., NAzer, N., Wellman, B. (2000), Netting scholars: online and offline, American Behavioral Scientist. $44: 1752-74$.

KOKU, E. F., Wellman, B. (2002), Scholarly networks as learning communities : The case of technet. In: S. BARAB, R. Kling (Eds), Designing Virtual Communities in the Service of Learning. Cambridge: Cambridge University Press, pp. 299-337.

KrausKopf, M., Vera, M. (1997), Assessment of scientific profiles and capabilities of Ph.D. programs in Chile : a Scientometric approach, Scientometrics, 40 (3) : 569-577.

Krauskopf, M. KrausKopf, E., MÉNDEZ, B. (2007), Low awareness of the link between science and innovation affects public policies in developing countries : The Chilean case, Scientometrics, 72 (1) : 93-103

Kretschmer, H., Aguillo, I. F. (2004), Visibility of collaboration on the Web, Scientometrics, 61 (3) : 405-426.

LAZINGer, S. L., BAR-ILAN, J., PERITZ, B. C. (1997), Internet use by faculty members in various disciplines: a comparative case study, Journal of the American Society for Information Science, 48 (6) : 508-518.

LABAnd, D. N., Tollison, R. D. (2000), Intellectual collaboration, The Journal of Political Economy, $108: 632-662$.

LINDHOLM-ROMANTSCHUK, Y., WARNER, J. (1996), The role of monographs in scholarly communication : an empirical study of philosophy, sociology and economics, Journal of Documentation, 1996, 52 (4) : 391.

LiN, N. (2001), Building a Network Theory of Social Capital. In: N. LIN, K. CoOK, R. BuRT (Eds), Social capital: theory and research. New York: Aldine de Gruyter, pp. 3-29.

Merton, R. (1968), The Matthew affect in science, Science, $159: 56-63$.

Meyer, J. B., Wattiaux, J. P. (2006), Diaspora knowledge networks: vanishing doubts and increasing evidence, International Journal on Multicultural Societies, 8 (1) : 4-24.

Meneghini, R., Mugnaini, R., PACKer, A. L. (2006), International versus national oriented Brazilian scientific journals, A scientometric analysis based on SciELO and JCR-ISI databases, Scientometrics, 69 (3) : 529-538.

Moody, J. (2004), The structure of a social science collaboration network : disciplinary cohesion from 1663 to 1999 , American Sociological Review, $69: 213-238$.

Mullins, J. AdAms, R., Halliwell, J., Milligen, L. (2000), Science, Technology, and Innovation in Chile. Ottawa: IDRC Books.

Murray, S. O., Poolman, R. C. (1982), Strong ties and scientific literature. Social Networks, 4 : $225-232$. 
DUQUE \& AL.: Internet practice and professional networks in Chilean science

Nowotny, H. Peter Scott, P., GibBons, M. (2001), Re-thinking science: knowledge and the public in an age of uncertainty. Cambridge: Polity Press.

Olson, G. M., Zimmerman, A., Bos, N. (2008) (Eds), Science on the Internet. Cambridge: MIT Press.

Palackal, A., ANderson, M., Miller, P., Shrum, W. (2006), Internet equalizer? gender stratification and normative circumvention in science, Indian Journal of Gender Studies, 14 : 231-257

Quan-HaAse, A., Wellman, B. (2004), How does the Internet affect social capital? In: M. HuYsman, V. Wulf (Eds), Social Capital and Information Technology. Cambridge: MIT Press, pp. 113-32.

REAGANS, R., MCEviLY, B. (2003), Network structure and knowledge transfer : the effects of cohesion and range, Administrative Science Quarterly, 48 (2) : 240-267.

RoBINSON, J. (2003), Introduction to issues 4 and 5 digital divides : past, present and future, IT \& Society, 1 : i-xiv.

Rogers, E., Diffusion of Innovations, 5th Edition. New York: Free Press, 1995.

SAGASTI, F. (1973), Underdevelopment, science and technology : the point of view of the underdeveloped countries, Science Studies, $3: 47-59$.

Sagasti, F., Prada, F., Casabonne, U., Bazan, M. (2003), The Sisyphus Challenge: Knowledge, Innovation and the Human Condition in the 21st Century. Lima: FORO Nacional/International.

SCHAUDER, D., (1994), Electronic publishing of professional articles : attitudes of academics and implications for the scholarly communication industry, Journal of the American Society for Information Science, 45 (2) : 73-100.

Schотт, T. (1993), World science: globalization of institutions and participation, Science. Technology \& Human Values, $18:$ 196-208.

SHRUM, W. (2005), Reagency of the internet, or, how I became a guest for science, Social Studies of Science, $35(5): 723-754$

Shrum, W., BegGS, J. (1997), Methodology for studying research networks in the developing world: generating information for science and technology policy, Knowledge and Policy, $9: 62-85$.

Shrum, W., CAMPION, P. (1998), Are scientists in developing countries isolated? Science, Technology and Society, $5: 1-34$.

Shrum, W., ShenhaV, Y. (1995), Science and technology in less developed countries. In: S. JaSANOFF, G. MARKLE, J. PETERSON, T. PINCH (Eds), Handbook of Science, Technology, and Society. Newbury Park: Sage.

SMith-DOERR, L. (2004), Flexibility and fairness: effects of the network form of organization on gender equity in life science careers, Sociological Perspectives, 47 : 25-54.

Sooryamoorthy, R., Duque, R. B., Ynalvez, M., Shrum, W. (2007), Scientific collaboration and the Kerala model : does the Internet make a difference? Journal Of International Development, 19 : 982-996.

Sproull, L., Kiesler, S. (1991), Connections. Cambridge: MIT Press.

Talua, S., SAVolainen, R., Maula, H., (2004), Field differences in the use and perceived usefulness of scholarly mailing lists. IR Information Research, 10 (1). URL: http://informationr.net/ir/10-1/paper200.html

UzzI, B. (1996), The sources and consequences of embeddedness for the economic performance of organizations, American Sociological Review, 61: 674-698.

VeSSURI, H. (1987), The social study of science in Latin America, Social Studies of Science, 17 : 519-554.

VOHORA, S. B., VOHORA, D. (2001), Why are Indian journals' impact factors so low? Nature, 412 (6847) : 583.

VooRBIJ, H. J. (1999), Searching scientific information on the Internet: a Dutch academic user survey, Journal of the American Society for Information Science, 50 (7) : 598-615.

WALSH, J., BAYMA, T. (1996), Computer networks and scientific work, Social Studies of Science, 26: 661-703.

Wellman, B., Salaff, J., Dimitrova, D., Garton, G., Gulia, G., Haythornthwaite, C. (1996), Computer networks as social networks: collaborative work, telework, and virtual community, Annual Review of Sociology, 22 : 213-238.

Ynalvez, M., Duque, R., Sooryamoorthy, R., Mbatia, P., Dzorgbo, D., Shrum, W. (2005), Productivity patterns and Internet use and diversity among developing world scientists, Scientometrics, $63: 39-47$.

YNALVEZ, M., Shrum, W. (2006), International training and the digital divide : computer and email use in the Philippines, Perspectives on Global Development \& Technology, 5 : 277-302.

Xie, Y., Shauman, K. A. (2003), Women in Science: Career Processes and Outcomes. Cambridge: Harvard University Press.

ZuCKerman, H. (1996), Scientific Elite: Nobel Laureates in the United States. New Brunswick: Transaction Publishers. 